\title{
Chapter 5 \\ Perverse Expertise and the Social Unconscious in the Making of Crisis
}

\author{
Richard Peet
}

This chapter stresses the social construction of the knowledge guiding social action. I focus on social construction as opposed to the individual's psychology of knowledge. The individual always has his or her own mentality, but what matters in the making of history are the broad social and cultural trends in thought, imagination, and comprehension. Further, I discuss social construction as it is meant in the critical tradition-Marx's ideology, Gramsci's hegemony-whereby class forces lead, direct, and control the production of knowledge. Knowledge production serves a class interest. As Marx and Engels (1845/2004) put it,

The ideas of the ruling class are in every epoch the ruling ideas, i.e. the class which is the ruling material force of society, is at the same time its ruling intellectual force. The class which has the means of material production at its disposal, has control at the same time over the means of mental production, so that thereby, generally speaking, the ideas of those who lack the means of mental production are subject to it. The ruling ideas are nothing more than the ideal expression of the dominant material relationships, the dominant material relationships grasped as ideas; hence of the relationships which make the one class the ruling one, therefore, the ideas of its dominance. (p. 64)

If the problems that beset capitalism result from the actions of capitalists-if the financial crisis that began in 2007 was caused by speculation by finance capitalists - then, the dominant interpretations will be those of the causal agents.

The rush of contemporary events is thus testing the ideas available for understanding them. This testing holds for the ideas developed to think through the immediate onslaught of rebellions, crises, and catastrophes. It also holds for the concepts needed to guide a more long-term movement into a different kind of society. Narrowly economic categories are insufficient for thinking about society as a whole. At the least, political-economic-cultural ideas are needed. Clearly, one cannot just regard a single country to be a society and must therefore consider geoeconomic or

\footnotetext{
R. Peet $(\square)$

Graduate School of Geography, Clark University, Worcester, MA, USA

e-mail: rpeet@clarku.edu
} 
geopolitical notions-or rather, geopolitical-economic concepts-adequate for a globalized existence. A new, critical conceptual apparatus is needed. But this critical conception is prevented by hegemonic control that a combination of perverse expertise and mass social unconsciousness exerts over imaginaries. At the juncture between modern knowledge and practical action lies expertise. When the mass mind loses its capacity to think rationally, the outcome is social unconsciousness. The elite practice perverse expertise, and the masses respond unconsciously. This mindset moves capitalist society into an era of perpetual crisis.

\section{Neoliberalism, Finance Capitalism, and Crisis}

I offer a proposition worthy, perhaps, of consideration. Several major, powerful blocs of countries have changed from societies with economies characterized by industrial capitalism to a new kind of society one might call finance capitalism. In the United States, the timing of this transformation is clear. Profits from manufacturing were far larger than profits from other corporate sectors until the 1980s, when profits in FIRE corporations (finance, insurance, and real estate) all of a sudden grew rapidly. They overtook those in manufacturing in the 1990s and have remained greater ever since. Financial corporations are now the dominant economic institutions in capitalist societies that have transitioned from production to the provision of services, especially financial services (Peet, 2011).

This transition results from secular change in the distribution of income. Figure 5.1, derived from U.S. income-tax statistics computed by Emmanuel Saez from the University of California, shows that the $1 \%$ of the U.S. population at the highest end of the income scale received $15-25 \%$ of total income in the Liberal period of U.S. capitalism (1917-1941). For the subsequent 40 years under Keynesian capitalism, that group received a fairly steady $10 \%$, a figure that began to rise suddenly in the early 1980s, under Neoliberalism, reaching 20-24\% in the 2000s. Economic growth since 1980 has almost exclusively produced higher incomes for the already rich (Piketty \& Saez, 2003). At the other end of the class spectrum, real incomes have fallen for the poor and have remained steady for just about everyone else. Increasing inequality is the central socioeconomic characteristic of finance capitalism.

Finance capitalism exercises power by controlling access to the markets through which capital accumulations become investments, directing flows of capital (e.g., equity purchases, bond sales, and direct investment) to places and users approved by the financial analytic structure of the banks, investment firms, and bond sellers on Wall Street and in the City of London. In terms of expertise, it is the investment analyst's global gaze, representing the confidence of the market, by which societies and economies are ordered, ranked, and adjudicated. Although investor confidence is presented by the business media as a neutral, technical, and necessary factor-in everyone's best long-term interest-it is actually a committed, financial capitalist interest based on utterly biased knowledge. An instructive example is the global bond market. The interest paid on sovereign bonds is determined by the risk of 


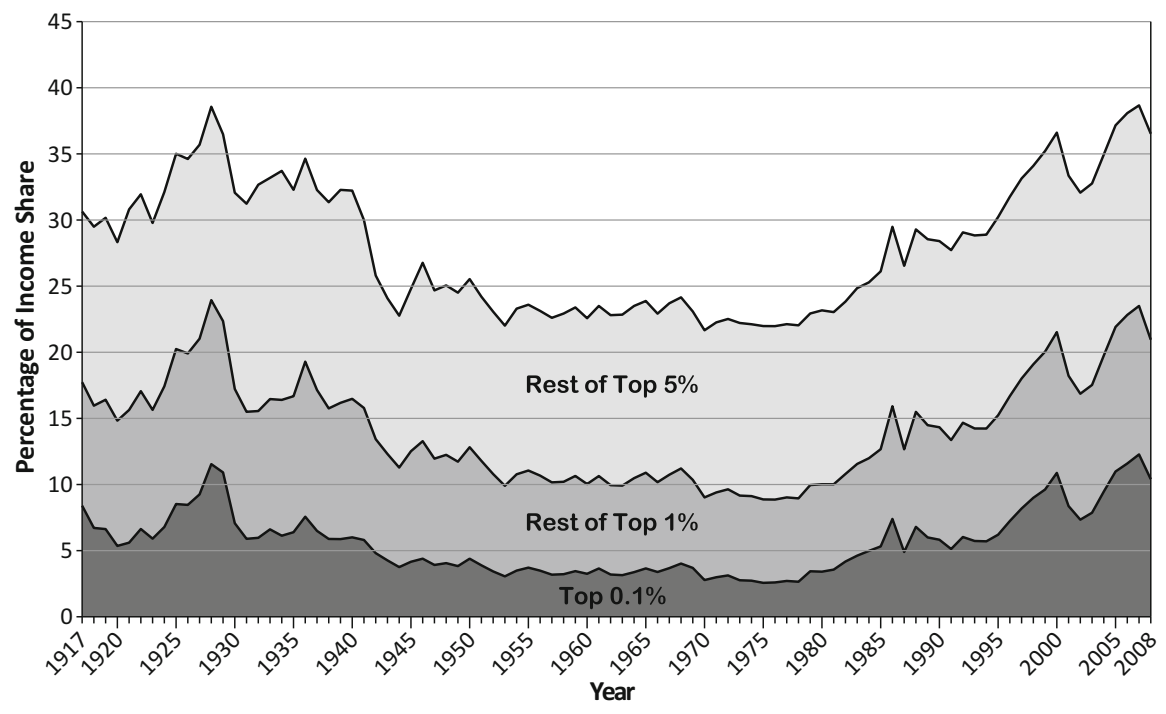

Fig. 5.1 Percentage income (including capital gains) going to the three highest income groups, United States, 1917-2008. (Source: Designed and drawn by the author. Statistical data from Alveredo, Atkinson, Piketty, \& Saez (2011))

default, with experts employing formulae stemming from long experience measured statistically - apparently scientific and necessary. Yet it is actually a few thousand experts representing the interests of accumulated capital who tell governments how to run their economies. At the very least, they represent undemocratic expertise.

At the confluence of knowledge and action lies expertise, by which is meant high-quality, specialized, theoretical, and practical knowledge. The process that produces sophisticated, but inimical, knowledge is what I call perverse expertise. It is expertise in that some of the world's finest minds, such as professional economists, do the intellectual and practical modeling and are well paid and respected for doing so. The process is perverse because knowledge is accumulated in order to continue augmenting the incomes of already wealthy people, the capitalist class. The only valid economic reason for gross distortions in income distribution of the kind that characterizes neoliberal, finance capitalism is that wealthy people are so rich that they cannot possibly spend all the money they receive and are therefore forced to save. The resulting vast accumulation of saved incomes becomes the main source of investment capital. Properly invested, capital can be used for research and innovation that results in more productive or sustainable economies. Badly invested, capital can be used for speculation that results in unstable economies. Knowledge and expertise make the difference.

Accordingly, Neoliberalism is a way of running the economy that produces dramatic price rises on the stock exchange, where the rich put their money to make ever more of it. But stocks and shares are a relatively safe bet compared to Neoliberalism's irrational exuberances, such as the sprawling financial apparatus surrounding the 
swollen credit market. Disaster strikes when, as in 1929 and 2007, the amount of money going to the $1 \%$ superrich approaches $25 \%$ of total income generated in the country, far exceeding requirements for productive investment and necessitating speculation to enhance returns. For the price of high returns is eternal risk. Any investment fund that does not generate quick and large returns and that thereby avoids extreme gambles suffers disinvestment in highly competitive markets, where money changes hands in a computer-aided flash. There is thus a competitive compulsion for experts to be ever more daring as they seek to maximize returns that temporarily attract investment. Financial managers, who oversee capital accumulations, compete for control over assets by promising these high returns. Those who fail to deliver high profit rates disappear to be replaced by even more aggressive investment analysts. Debt, speculation, hazard, and fear are thereby structurally endemic to finance capitalism in what Walks (2010) calls "Ponzi Neoliberalism." Fear itself becomes the source of further speculation, as with buying gold or futures. Debt and gambling spread from Wall Street into all sectors of society-house prices, state lotteries, casinos, numbers games, bingo at the church hall, sweepstakes, and Pokemon cards. Everyone gambles, even children. Production, consumption, economy, culture, and the use of environments are subject to an ever more removed, abstract calculus of power in which ability to contribute to short-term financial profit becomes the main concern. The structure of the system compels expertise into perversity. The particular thinker, with his or her own psychological structure and thinking processes, has little to do with structural compulsions in the relations between knowledge and action.

The interlocking of these speculations is the source of their intractability. The financial crisis that began in 2007 was thus marked by vastly overpriced housing, particularly near booming financial centers; competition among financial institutions to offer easy credit that made many people hopelessly indebted; the bundling of home mortgages and other debts into tradable paper; exorbitant levels of leveraging; and the use of assets whose value can disappear in an instant to securitize other, even chancier investments. It was not just that crisis spread from one area to another. It was that crisis in one area (such as the inevitable end to the housing price bubble) had exponential effects on the others (investment banks that were overextended into high-risk speculation) to the degree that accumulated losses tested the capacity of even client states and governance institutions to rescue the situation. In a nutshell, inequality is not merely unethical, it is dangerous. The combination of debt and speculation, deriving from inequality, produces an inevitable tendency toward repeated financial crises.

\section{Buying the State}

Why are the colossal incomes of the already rich not taxed out of existence? How can extreme inequality survive in democracies where people are, at least apparently, free to vote for anyone they choose? The main thing about so-called free elections 
is that they are not free. Elections are expensive. Public opinion is made by media persuasion. Political images are costly to produce, in part because sharp minds ponder every persuasive aspect, ransack each emotion, and raid the collective memory to sell candidates for office. Such images are expensive to distribute, especially because the image of the politician has to compete with images of other commodities that taste nice and look even better than the politician. Politicians therefore have to raise a great deal of money to run for office when elections are decided almost exclusively by image projection in Fordist societies.

In 1976 and 1980, the last U.S. elections under Keynesian capitalism, presidential candidates collectively raised and spent about $\$ 1.75$ billion per election. As Neoliberalism took hold, the cost of elections soared. In the 2008 U.S. presidential election, candidates collectively raised ten times more-just under $\$ 17.49$ billion, with the total cost of the election amounting to just over $\$ 5.28$ billion. In the 2010 midterm elections, congressional candidates raised $\$ 1.08$ billion-and senatorial candidates, \$ 742 million - in an election fought almost entirely on the basis of attack ads (data from Center for Responsive Politics, n.d.). The 2012 presidential elections made even these enormous amounts seem like pocket money. In the few months of the early presidential campaign up to the end of June 2012, and before things really intensified, President Obama spent $\$ 400$ million, and eventually $\$ 1$ billion. In addition, the U.S. Supreme Court, in Citizens United vs. FEC (2010), ruled that under the First Amendment of the U.S. Constitution (which deals with the freedom of speech) the government could not restrict the size of corporate donations to Super Pacs (Political Action Committees) that indirectly support candidates for public office by supporting causes that they stand for. A billion dollars is needed to run a high-level campaign.

Where does one acquire a billion dollars to run a campaign or support a cause? Answer: from people who have a billion dollars. About one tenth of $1 \%$ of the U.S. adult population (231,000 people) donate over $\$ 2000$ each to political campaigns, and these donations make up $75 \%$ of the total contributions; a mere 26,000 people donate $36 \%$ of total contributions (Center for Responsive Politics n.d.). In other words, a candidate must raise hundreds of millions of dollars from 200,000 rich people to be able to run a campaign. Candidates who do not appeal to the rich or who are not wealthy themselves never have a chance. They raise a few million dollars at most (independent candidate Ralph Nader raised $\$ 4$ million in 2008), they cannot run television ads, they are not present at media debates, and most of the electorate never hears of them. Rich people choose the political candidates who run for office. Under finance capitalist democracy, the electorate decides which rich people's candidates are elected to office. And the information spread by costly advertising? Most messages are attack ads presenting unfavorable information about the candidate or cause they oppose. Most of the rest are image ads presenting favorable pictures of the candidate they support. The real content, by which I mean substantiated and sustained information about a candidate's positions and policies, hardly appears. Images, attack ads, and the like constitute perverse political knowledge produced by perverse expertise. It produces perverse democracy. 
Once in office, politicians are kept in line by lobbying. Companies, labor unions, and other organizations, in addition to making campaign contributions, spend $\$ 3.5$ billion each year on efforts to influence the U.S. Congress and federal agencies. In the period between 1998 and 2010, the insurance, business association, and securities sectors spent $\$ 33.6$ billion on lobbying, whereas labor spent about $\$ 30$ million a year. Some 130 former members of congress are lobbyists, and lobbies employ nearly half the politicians and congressional aides who return to the private sector. Such money and connections do not spread scientific or factual knowledge. They project information based on superficial, biased knowledge thought up to support powerful interests. Lobbyists are yet another example of perverse political expertise.

\section{Finance Capitalism and Environmental Crisis}

During the unusually hot summers of 2010, 2011, and 2012, capitalist society fell prey to two crises: an economic depression that states or markets could not end and a sequence of environmental tragedies brought on by global warming. Did the two crises coincide by mere chance? Or did they stem systematically from the same structural causes? The answer might seem obvious were it not for media that must confuse on causation as they inform on details. Both economic depression and environmental catastrophe result from the extreme risks that must be taken by prominent actors under finance capitalism-meaning that anyone who does not stake everything is eliminated from power. Crises that threaten humanity are structurally endemic to finance capitalism.

Financial and economic crisis lead to periodic recessions, depressions, and downturns punctuated by hopelessly optimistic upturns in the markets, bringing on the terrible social outcome of millions of people losing their jobs, homes, and dignity. But the worst is yet to come as the environment strikes back. The hazards endemic to finance capitalism extend to precarious environmental relations. The bearers of capitalist culture become risk-ridden, short-term in memory and anticipation, and careless about consequences. They live for the moment, without regard for the environmental future. Production, consumption, the economy in general, and the use of environments are subject to a remote, abstract calculus of power wherein the ability to promote short-term financial profit becomes primary and long-term impacts are not so much ignored as glossed over through sophisticated corporate advertising, think-tank excuses, and pseudogreen propaganda ("We, too, care about the environment"). By generating above-average profits, corporate leaders who make environmentally perilous decisions - to drill in deep water, for instance-win the investor confidence that enables them to borrow, invest, and expand and allows them to pay their upper management well. CEOs who demonstrate an environmental conscience do not win the market's confidence. Environmental risk (mitigated by quality public relations to excuse the occasional mistakes) represents the frontier in profit-making and business success. Every time a disaster such as British Petroleum's 
2010 oil spill in the Gulf of Mexico is cleaned up, excused, and forgotten, the agents of the risk business just become more knowledgeable and slicker at its politicocultural operations. As BP was restoring investor confidence in the summer of 2010, the company announced that it was selling its onshore drilling operations to concentrate even more on deep-sea drilling. The danger that produces economic catastrophe also creates environmental crises.

The neoliberal globalization that has deindustrialized the First World and industrialized parts of the Third World—Brazil, South Korea, China, and India—has resulted in a spectacular globalization of environmental destruction. Globalization of this neoliberal, financial kind means that economic growth rates slow in the deindustrialized center but accelerate rapidly (rates of $8-10 \%$ a year) in some peripheral industrializing countries. China's economy grew 14-fold between 1980 and 2006 to the equivalent of a GDP of $\$ 4.4$ trillion, and India's economy grew sixfold, to $\$ 1.2$ trillion, with carbon dioxide emissions increasing proportionately. China's carbon dioxide emissions from burning fossil fuels amounted to 407 million metric tons in 1980 and nearly 2.25 billion in 2010; India's went from 95 million metric tons in 1980 to 564 million in 2010 (Boden \& Blasing, 2012).

Much of this production and pollution is connected to consumption in the First World. Some $40 \%$ of China's product is exported, as is $20 \%$ of India's, and both economies have become dramatically more export oriented. These statistics show the globalization of an economy still centered on consumption in the high-income countries. This fixation has led to an intensification of pollution's globalization, as evidenced by carbon dioxide emissions. In 2010 global fossil-fuel carbon emissions amounted to 9.13 billion metric tons of carbon. In global terms, more than 500 billion metric tons of carbon have been released into the atmosphere from the burning of fossil fuels and cement production since 1750, and half of these emissions have happened since the mid-1970s, when it was already known that greenhouse gasses caused global warming - perverse environmental knowledge.

The point is that environmental pollution is driven by economic necessity under capitalism. It is necessary to pollute so that money can be made. Within the existing politicoeconomic context, only economic recession can bring about a drastic decrease in pollution. Indeed, global carbon dioxide emissions from burning fossil fuels temporarily declined by $5.9 \%$ from 2008 through 2009 . This reduction came about because of a $2.5 \%$ fall in global GDP, a decrease of $11.5 \%$ in the manufacturing production index, and a reduction of $40 \%$ in raw steel production. Yet it is politically impossible for parties or governments to suggest, in effect, that the necessary price of ending environmental destruction is a declining economy. The solution is to elevate discussion from the national to the international scale. Upward displacement in the environmental discourse necessarily takes the form of UN conferences, Earth summits, and unenforceable protocols. Economic necessity produces endless political evasion of the environmental issue. Yet under Neoliberalism the significance of government regulation of development - and development's relations with the environment - is diminishing because of the intensification of neoliberal and mass beliefs, including mass beliefs, about government, markets, and policies. Hence, the Tea Party movement in the United States is founded on the idea of reducing the size 
and interventional zeal of government at a time when state intervention through environmental regulation is all that exists in the way of collective response to the destruction of nature.

In brief, environmental knowledge has escalated as environmental destruction has intensified. It is a case of perverse knowledge.

\section{Social Unconsciousness}

Were these issues the only ones, the world's people might still survive to criticize the system yet again. The business-state-media power complex, led by finance capital and driven by the quest for superprofits and fantastic incomes, cannot be opposed with any degree of success except by social movements arising from an informed, enraged, and rational populace. There has to be a critical, rational, activist We-for-Us-to-save-the-world. Yet the other, popular side of finance capitalism is consumptive excess enabled by the cheap commodities that flood in from globalized production. The priority of social reproduction shifts from socializing people to become workers to socializing people to become consumers. A new type of human being is emerging, the consumptive person. The culture of overconsumption produces mass, popular apathy (I like, rather than I think). Overconsumption is a social addiction, a radical, selfish individualism that I characterize as the social unconscious. It is unconscious in that conscious awareness is missing, has not been constructed, has not been allowed to develop even from the interpretation of everyday experience (common sense), and it is social in that many people share similar characteristics. The culture of overconsumption is not so much a case of deliberately producing mass stupidity, although mass advertising comes close to a corporate conspiracy. It is more that the trivialization of everyday life produces unconsciousness. Utter trivialization gives rise to a new kind of soft, shallow, compliant personality encased in the kind of fat body that results from total absence of self-control-35.7\% of American adults are obese, as are 17\% of American children (Adult Obesity Facts, 2013). Reality is a show. Entertainment is all that is. Because every commodity must have a body to bear its message and because every service is energy-intensive, overconsumption, overproduction, and the concomitant overuse of resources create environmental risk for society as a whole.

Essentially, the ability to respond in a radical, collective, socially rational wayto control an activist, interventionist state democratically, for instance-has been consumed away in vast segments of the population living in the global centers of power. And the leading ideas produced by experts in the service of power are ideological diversions rather than means of collective rational intervention.

My conclusion is that the intersecting economic and environmental crises will continue ad infinitum because the existing hegemonic knowledge cannot guide effective social action. 


\section{References}

Adult Obesity Facts. (2013). Retrieved October 16, 2013, from Centers for Disease Control and Prevention, Division of Nutrition, Physical Activity, and Obesity Website at http://www.cdc. gov/obesity/data/adult.html

Alveredo, F., Atkinson, T., Piketty, T., \& Saez, E. (2011). The world top income database. Retrieved from http://g-mond.parisschoolofeconomics.eu/topincomes/

Boden, T., \& Blasing, T. J. (2012). Record high 2010 global carbon dioxide emissions from fossilfuel combustion and cement manufacture. Retrieved from the U.S. Department of Energy, Office of Science, Dioxide Information Analysis Center Website at http://cdiac.ornl.gov/ trends/emis/prelim_2009_2010_estimates.html

Center for Responsive Politics. (n.d.). https://www.opensecrets.org Accessed several times from 2010 to 2011.

Citizens United vs. Federal Election Commission, No. 08-205. U.S. 310. Argued March 24, 2009-Reargued September 9, 2009—Decided January 21, 2010.

Marx, K., \& Engels, F. (2004). The German ideology: Part one with selections from parts two and three and supplementary texts (C. J. Arthur, Ed.). New York: International Publishers. (Original work published 1845)

Peet, R. (2011). Contradictions of finance capitalism. Monthly Review, 63(7), 18-32. Retrieved from http://monthlyreview.org/2011/12/01/contradictions-of-finance-capitalism

Piketty, T., \& Saez, E. (2003). Income inequality in the United States, 1913-1998. Quarterly Journal of Economics, 118, 1-39. doi:10.1162/00335530360535135

Walks, A. (2010). Bailing out the wealthy: Responses to the financial crisis, Ponzi Neoliberalism, and the city. Human Geography, 3(3), 54-84.

Open Access This chapter is distributed under the terms of the Creative Commons Attribution 4.0 International License (http://creativecommons.org/licenses/by/4.0/), which permits use, duplication, adaptation, distribution and reproduction in any medium or format, as long as you give appropriate credit to the original author(s) and the source, provide a link to the Creative Commons license and indicate if changes were made.

The images or other third party material in this chapter are included in the work's Creative Commons license, unless indicated otherwise in the credit line; if such material is not included in the work's Creative Commons license and the respective action is not permitted by statutory regulation, users will need to obtain permission from the license holder to duplicate, adapt or reproduce the material.

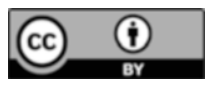

